DOE/METC/C-96/7225

Title:

Statistical Kinetics for Pulverized Coal Combustion

Authors:

Robert H. Hurt

Melissa M. Lunden

Ellen G. Brehob

Daniel J. Maloney

Conference Title:

26th International Symposium on Combustion

Conference Location:

Naples, Italy

Conference Dates:

$7 / 28 / 96$ to $8 / 2 / 96$

Conference Sponsor:

The Combustion Institute 


\section{DISCLAIMER}

This report was prepared as an account of work sponsored by an agency of the United States Government. Neither the United States Government nor any agency thereof, nor any of their employees, makes any warranty, express or implied, or assumes any legal liability or responsibility for the accuracy, completeness, or usefulness of any information, apparatus, product, or process disclosed, or represents that its use would not infringe privately owned rights. Reference herein to any specific commercial product, process, or service by trade name, trademark, manufacturer, or otherwise does not necessarily constitute or imply its endorsement, recommendation, or favoring by the United States Government or any agency thereof. The views and opinions of authors expressed herein do not necessarily state or reflect those of the United States Government or any agency thereof.

This report has been reproduced directly from the best available copy.

Available to DOE and DOE contractors from the Office of Scientific and Technical Information, 175 Oak Ridge Turnpike, Oak Ridge, TN 37831; prices available at (615) 576-8401.

Available to the public from the National Technical Information Service, U.S. Department of Commerce, 5285 Port Royal Road, Springfield, VA 22161; phone orders accepted at (703) 487-4650. 


\title{
Statistical Kinetics for Pulverized Coal Combustion
}

\author{
Robert H. Hurt ${ }^{\dagger}$ \\ Division of Engineering, Brown University \\ Providence RI 02912 \\ Melissa M. Lunden \\ . Combustion Research Facility, Sandia National Laboratories \\ Livermore, CA 94550 \\ Ellen G. Brehob and Daniel J. Maloney \\ U.S. Department of Energy \\ Morgantown Energy Technology Center, Morgantown, WV 26507-0880 \\ $\dagger$ corresponding author: Phone: (401) 863-2685 (USA) \\ FAX: (401) 863-1157 \\ E-mail: Robert_Hurt@brown.edu

\begin{abstract}
Preferences
author's preference is for oral presentation

and for the Colloquium on Coal and Organic Substances
\end{abstract}

Word count

\begin{tabular}{|c|c|c|}
\hline & Word count & \\
\hline $\begin{array}{l}\text { Text: } \\
\text { References: } \\
\text { Equations: } \\
\text { Table and Figures: }\end{array}$ & $\begin{array}{l}264 \text { lines@ } 12 \text { equivalent words per line } \\
53 \text { lines@ } 12 \text { equivalent words per line } \\
4 @ 21 \text { equivalent words per equation } \\
7 \text { figs. and } 1 \text { table @ } 200 \text { equivalent wds each }\end{array}$ & $\begin{array}{r}3168 \\
636 \\
84 \\
1600\end{array}$ \\
\hline Lall & & 5488 \\
\hline
\end{tabular}


Coal is a heterogeneous substance whose structure and properties are highly variable on the length scale of the particle sizes used in suspension-fired combustion systems. For certain applications the statistical variations among particles can play an important role. In this paper, three specialized, single-particle techniques are applied to quantify the variations in combustion reactivity and char particle density within pulverized char particle populations. Reactivity variations are investigated through captive particle imaging experiments and entrained flow reactor experiments employing single-particle optical diagnostics. Single-particle density variations are determined directly by a novel technique based on an electrodynamic microbalance equipped with an automated video imaging and image processing system.

From these data, a coal-general statistical kinetic model is developed and validated against a large set of single-particle temperature measurements for ten coals of various rank burning in three different combustion environments. The model incorporates a single empirical parameter describing the heterogeneity in reactivity and can adequately describe the entire database using a single coal-independent value of this parameter. The use of the model is demonstrated in a series of numerical simulations of complete burnout process for size-classified and polydisperse fuel samples. The simulations show that incorporating statistical kinetics has an important effect on burnout predictions in certain cases, the importance increasing with decreases in temperature, mean reactivity, and breadth of the particle size distribution. 


\section{INTRODUCTION}

Coal is a heterogeneous substance whose structure and properties are highly variable on the length scale of particle sizes used in suspension-fired combustion systems. Most rate processes in combustion have traditionally been described by mean kinetics - formulations that do not explicitly account for these particle-to-particle variations in properties or reactivity. In some coal technologies, however, the statistical variations may play an important role, an example being in pulverized coal combustion, where residual, or unburned, carbon in fly ash typically represents less than $1 \mathrm{wt}-\%$ of the coal feed to a boiler. Even at the level of $1 \%$ carryover, unburned carbon can have a negative impact on ash utilization options and on overall power station economy. Aware of coal's intrinsic heterogeneity, many combustion researchers have hypothesized that the small fraction of the fuel that remains unburned originates from the least reactive, largest, and/or most dense particles in the original fuel. (Particle density increases the amount of carbon to be consumed by oxidation, thus increasing burnout time for a given reactivity). The goal of the present work is to assess this "heterogeneity hypothesis" through directemeasurement of the statistical variations in reactivity and density exhibited by single pulverized char particles $\left(\mathrm{d}_{\mathrm{p}} \sim\right.$ $100 \mu \mathrm{m})$.

Most combustion studies have reported mean kinetics[1-5], even in cases where the raw measurements were performed on single particles[5]. Several groups have specifically investigated fuel heterogeneity through single particle combustion experimentș[6-9], through studies on lithotypes or maceral concentrates[10,11], or through reflected light analysis of coal and combustion residues[12-17]. Many of these latter studies focus on the relationship between coal petrology and carbon burnout with a special emphasis on the possible role of inertinite-group macerals, which often form char particles that are more dense and less reactive than the mean. In a study of residual carbon from power plants burning Australian coals, Bailey et al.[12] report a strong positive correlation between unburned carbon levels and coal rank, and a lesser but significant positive correlation between unburned carbon levels and char particle densities. Overall, the existing body of work indicates that pulverized coal particles vary significantly in petrology, organic composition, pore structure, mineral matter[18], and particle morphology, and that these variations lead to large particle-to-particle variations in char burning rates and burnout times.

In this paper three specialized, single-particle techniques are applied to quantify the variations in combustion reactivity and density in pulverized char particle populations. Reactivity variations are investigated through captive particle imaging experiments and entrained flow reactor experiments 
using single-particle optical diagnostics. Density variations are determined directly by a novel technique based on an electrodynamic microbalance equipped with an automated video imaging and image processing system[19]. From these data, a coal-general statistical kinetic model is developed and validated against data on ten U.S. coals. The model is designed to be useful for a variety of quantitative combustion calculations; it is used here as an example to numerically explore the role of heterogeneity in the carbon burnout process.

\section{SAMPLES AND EXPERIMENTAL PROCEDURES}

This study focuses on a set of ten U.S. coals from the Pennsylvania State Sample Bank ranging in rank from lignite to low-volatile bituminous. This coal set has been studied previously [5] and an extensive characterization is available elsewhere[20,21]. Captive particle imaging experiments were performed on 125 - $250 \mu \mathrm{m}$ coal particles from four of the ten parent coals: (Pocahontas \#3, lvb; Illinois \#6, hvb; Dietz, subbit; and Beulah lignite) and single-particle densities were measured for two coal char samples (Beulah and Illinois).

Previous publications have presented descriptions of each of the three experimental apparatus: the Sandia entrained flow reactor and optical diagnostic[5,20], the captive particle imaging (CPI) apparatus[22], and the electrodynamic balance and automated video imaging system[19]. The CPI technique provides video image sequences of the complete combustion lifetimes of $100-200 \mu \mathrm{m}$ particles resting on a low-density $\mathrm{Al}_{2} \mathrm{O}_{3}$-fiber gossamer suspended in a hot vitiated air stream of known temperature $(1250 \mathrm{~K})$ and gas composition ( $3-19$ mole-\% oxygen). The experimental procedure was the same as that described previously[21]. For each particle, the image sequences were processed to determine: (a) a swelling factor, (b) a maximum particle radiance temperature (as a measure of reactivity), and (c) the ratio of the ash particle size at the end of the sequence to the initial coal particle size, $\mathrm{d}_{\mathrm{a}} / \mathrm{d}_{\mathrm{c}}$. This last ratio is a convenient and useful indicator of initial ash content, although it cannot be quantitatively related to ash mass fraction due to variations in carbon and ash densities.

For the determination of particle densities, particle volumes and external surface areas were first measured by recording shadow images as a function of particle rotation angle[23]. Drag coefficient to mass ratios were then determined by analyzing the response of the particles to external perturbations[24]. This data was used to determine particle mass and density by applying a drag analysis for slightly deformed spheres[19]. For this study, measurements were made on a total of 120 char particles of nominal size 106-125 $\mu \mathrm{m}$, from raw and demineralized samples of PSOC-1493D, Ilinois \#6 coal and 1507D, Beulah lignite. Prior to demineralization or analysis, the young char samples were prepared in the entrained flow reactor by sampling at $47 \mathrm{msec}$ residence time, the approximate end of devolatilization. 


\section{EXPERIMENTAL RESULTS}

The analyses in this paper are based in part on raw data taken from the Sandia coal combustion database[20], comprising approximately 12,000 measurements of single-particle temperatures and sizes during combustion in the entrained flow reactor. The measurements were made on 50-150 $\mu \mathrm{m}$ diameter char particles from ten parent coals undergoing combustion in oxygen concentrations of 6 and 12 mole-\%, at gas temperatures of $1500-1650 \mathrm{~K}$, at particle temperatures of $1450-2000$ $\mathrm{K}$, and for residence times up to $120 \mathrm{msec}$. An example of this data is shown in Fig. 1, which plots mean particle diameters and temperatures for the ten chars superimposed on single particle data for one coal, Pocahontas \#3. The single particle data cover a wider range of temperatures than the entire set of mean temperatures, implying that, within the Pocahontas sample, there are particles with combustion behaviors typical of lignites as well as particle with combustion behaviors typical of high-rank (lvb) coals. The mean temperature and burning rate are crude descriptors of this complex behavior.

Previous analysis has shown that the temperature distributions at low conversion are caused primarily by reactivity differences inherent in the parent fuel, with variations in physical and transport properties making a much smaller contribution[25]. The distributions are stationary in the early stages of reaction (the statistical distribution properties are constant) making these data suitable for characterizing the initial heterogeneity in the parent fuel. At high conversion, the particle temperature distributions are strongly influenced by the presence of numerous lowtemperature particles identified by Mitchell[26] as highly-reacted, high-ash-content particles. This is a conversion-dependent effect that makes these distributions unsuitable for characterizing the initial heterogeneity in the parent fuel. For this analysis, therefore, we consider only that subset of the optical data for which bulk char carbon conversions are less than $45 \%$.

Figure 2 summarizes the single particle temperature statistics for the reduced data set, which forms the basis set for formulation and validation of the statistical kinetic model. The magnitude of the temperature variance plotted in Fig. 2 is a measure of the breadth of the distribution, and is seen to

$\dagger$ At the earliest residence time $(72 \mathrm{msec})$ a very small number of particles are often observed at or below the local gas temperature which are absent at the next measurement point $(95 \mathrm{msec})$. These particles are believed to be in the latter stages of transient heating at the earliest residence time, but to have reached their pseudo-equilibrium temperature by $95 \mathrm{msec}$. These few particles have a negligible effect on the overall temperature variance when it is broad, but can contribute significantly when the remainder of the distribution is narrow. Therefore, the few particles at the earliest residence time that are at or below the local gas temperature were removed from the raw data for these analyses. 
depend strongly on the parent fuel and combustion conditions, varying from $324 \mathrm{~K}^{2}(\sigma=18 \mathrm{~K})$ to $8650 \mathrm{~K}^{2}(\sigma=93 \mathrm{~K})$. To develop the statistical kinetic model, more information is needed about the origin of the reactivity distributions implied by Fig. 2, in particular about the origin of the lowreactivity tails of the distributions. If the low-temperature, low-reactivity particles are also the particles with high carbon density, their burnout times, which are related to the product of reactivity and density, will be extremely long. If on the other hand, the low-temperature, lowreactivity particles are those of unusually high ash content, their carbon contents will be low and their burnout times will be much shorter. Captive particle imaging experiments were therefore carried out on raw coals to allow simultaneous measurement of particle temperatures (which are indicators of particle reactivity), swelling factors (which are indicators of char particle density), and final ash particle sizes (which are indicators of ash content). The data from image processing were examined in search of possible correlations between the temperature, ash, and swelling measurements. No strong correlations were found for any of the coals between single-particle temperatures on the one hand, and ash contents, swelling factors, or particle sizes on the other.

From these experiments it is clear that, in the early stages of combustion, single particle reactivity varies greatly and is not closely related to ash content or swelling behavior. In particular, the lowest temperature (reactivity) particles observed were not unusual in either their apparent ash contents $^{\dagger}$ or in their swelling behavior. To first order, the distributions of reactivity, swelling factor, and ash content can be assumed to be mutually independent. - a key result that will guide the modeling work described in the next section.

The electrodynamic balance technique was used to make a series of 120 density measurements on single char particles of Beulah lignite and Illinois \#6 coal, both before and after demineralization. The single particle density data are summarized in Fig. 3. Significant variations are seen among the single-particles from a single coal char, and between the mean values for the two different coal chars.

\footnotetext{
T Note that this conclusion relates to the early stages of the combustion process, before significant numbers of highly-reacted, ash-rich particles appear. Highly oxidized particles with very high ash contents are theoretically expected and observed to have low global reactivities[22], and indeed are responsible for many of the low-temperature particles observed at high conversions[26].
} 


\section{MODEL FORMULATION}

In this section a statistical model is developed that describes the single particle temperature data set summarized in Fig. 2. In the model, variations in reactivity are represented as variations in single particle global preexponential factor, $A$, (g-carbon $/ \mathrm{s}-\mathrm{atm}{ }^{0.5}-\mathrm{cm}^{2}$-external-surface) with global activation energy and reaction order held constant across the particle population ${ }^{\dagger}$. Single particles are allowed to vary in size, $d_{p}$, reactivity, $A$, and carbon density $\rho_{c}$, defined as the mass of carbon per unit particle volume. The number fraction of particles in the incremental parameter space $d d_{p}$ $d A d \rho_{c}$ is given by $F\left(d_{p}, A, \rho_{c}\right) d d_{p} d A d \rho_{c}$, where the function $F\left(d_{p}, A, \rho_{c}\right)$ fully describes the particle population. The captive particle imaging results described above further suggest that $F\left(d_{p}, A, \rho_{c}\right)$ can be expressed as the product of three independent functions:

$$
F\left(d_{p}, A, \rho_{c}\right)=F_{d}\left(d_{p}\right) \cdot F_{A}(A) \cdot F_{p}\left(\rho_{c}\right)
$$

where $F_{d}$ is the particle size distribution, $F_{A}$ is the distribution of reactivities (preexponential factors), and $F_{\rho}$ is the distribution of char particle carbon densities. The distributions $F_{d}, F_{A}$, and $F \rho$ can be determined in separate experiments and then superimposed to form the complete input distribution using Eq. 1. This paper focuses on the determination of $F_{A}$ and $F \rho-$ the function $F_{d}$ can be measured directly by conventional techniques in powder technology.

The reactivity distribution function, $F_{A}$, is modeled as a gamma distribution, defined by:

$$
F_{A}(A)=\frac{e^{-\beta A}}{\Gamma(A)} A^{\alpha-1} \beta^{\alpha}
$$

where $\alpha$ and $\beta$ are the distribution parameters and $\Gamma(A)$ is the gamma function. Unlike the Gaussian distribution, which has a lower tail extending to negative reactivities, the gamma reactivity distribution, $F_{A}(A)$, is defined only for $A_{i}>0$. It also has the convenient property

$\dagger$ Variations in particle reactivity arise due to variations in the intrinsic reactivity, $k_{i}$, surface areas, $S$, and effective diffusion coefficients, $D_{\text {eff. }}$. The variations in intrinsic reactivity can affect the temperature dependent term (such as the activation energy, $E_{i}$, in Arrhenius kinetics) or the temperature independent term (such as the preexponential factor, $A_{i}$, in the case of Arrhenius kinetics). Of the four parameters $S, D_{e f f}, A_{i}, E_{i}$, variations in three of them ( $S$, $\left.D_{e f f}, A_{i}\right)$ appear as variations in the global preexponential factor, $A$. Only variations in $E_{i}$ will affect the global activation energy, $E$, and $E_{i}$ has been shown to fall within a relatively narrow range of values for a wide variety of impure carbons[27,28]. Therefore, the model is based on an explicit description of variations in $A$, as a convenient approximate representation of the total heterogeneity. 
that the mean and variance are simple functions of $\alpha$ and $\beta$ :

$$
\begin{gathered}
A_{\text {mean }}=\alpha / \beta \\
\sigma_{A}^{2}=\alpha / \beta^{2}
\end{gathered}
$$

The complete set of reactivity distribution functions for ten coals were determined as follows. Relationships between preexponential factors and particle temperatures were first determined by solving, for each combustion condition of interest, the coupled mass and energy transport equations describing burning char particles[5]. These calculation used a single global activation energy of $20 \mathrm{kcal} / \mathrm{mol}$ and a product ratio given by $C O / C O_{2}=A_{c} \exp \left(E_{c} / R T_{p}\right)$ where $T_{p}$ is the particle temperature, $A_{c}=3 \cdot 10^{8}$, and $E_{c}=60 \mathrm{kcal} / \mathrm{mol}$. For each coal, a mean value of the preexponential factor, $A_{\text {mean }}$, was determined to best match the mean particle temperatures measured optically. The distribution was then determined by choosing a value for the heterogeneity parameter, $\sigma_{A}$, computing $\alpha$ and $\beta$ by Eqs. 3 and 4, computing the distribution function by Eq. 2 , computing the temperature distribution from the coupled mass and energy balances, and then comparing the predicted temperature variances with the measured variances in Fig. 2. A NewtonRaphson algorithm was then used to find the single value of the heterogeneity parameter, $\sigma_{A}$, that minimizes the sum of squared residuals between the predicted and measured variances for the entire data set.

The model predictions are shown as dashed lines in Fig. 2. A single, coal-independent value of the heterogeneity parameter, $\sigma_{A}=3.9 \mathrm{~g}$-carbon $/ \mathrm{cm}^{2}-\mathrm{s}-\mathrm{atm}^{0.5}$, is seen to provide a good description of the entire set of single-particle temperature distributions. The success of the single parameter implies for this data set that the major effects of fuel heterogeneity on combustion can be usefully modeled without detailed coal-specific characterization. Fig. 4 gives an example comparison of measured and predicted particle temperature distributions, along with the gamma distribution of preexponential factors on which the prediction is based.

The success of this simple model indicates that the extent of fuel heterogeneity, judged by the value of $\sigma_{A}$, is nearly constant across this sample set, and that the wide range of temperature variances $\left(324\right.$ to $\left.8650 \mathrm{~K}^{2}\right)$ is due primarily to the varying combustion conditions. The largest temperature variances arise under conditions where the governing gas-particle transport relations exhibit a high sensitivity of particle temperature to reactivity. Such conditions include high oxygen concentrations and mean reaction rates far from the boundary layer diffusion limit. The success of the single value of the heterogeneity parameter, $\sigma_{A}=3.9 \mathrm{~g}$-carbon $/ \mathrm{cm}^{2}-\mathrm{s}$-atm ${ }^{0.5}$, suggests that the statistical model can serve as a useful general engineering tool even in the absence of coal specific 
data on heterogeneity. It is not yet known, however, if the single parameter can accurately describe the behavior of coals outside this sample set, in particular of coals outside North America with very different petrologies and geologic histories.

\section{COMBUSTION SIMULATIONS ·}

The statistical kinetic model is a useful tool for assessing the importance of heterogeneity under various conditions relevant to laboratory and commercial combustion processes. A computer code was written to simulate complete burnout processes for samples exhibiting particle-to-particle variations in size, reactivity, and density. The code contains a particle combustion model based on single film theory that accounts for swelling, diameter change during oxidation, ash content, gasto-particle heat transfer by radiation and convection, mass transfer, and global heterogeneous kinetics with a variable $\mathrm{CO} / \mathrm{CO}_{2}$ ratio in the primary products[20]. The burnout calculations were performed holding the reactivity, $A$, of each particle constant throughout conversion at its initial value. Single particle reactivities have in fact been observed to change[25] but that change is suppressed here in order to isolate and assess the effect of heterogeneity alone.

Figure 5 shows the effect of statistical kinetics on the burnout profiles of size-classified coal particles undergoing combustion in a simulated, one-dimensional laboratory reactor under two sets of conditions. The uniform and heterogeneous samples are seen to burn at comparable rates until a carbon conversion of $60-80 \%$ is reached, after which the curves diverge. For the less reactive coal (Pocahontas \#3) burning at the lower temperature $(1450 \mathrm{~K})$, incorporation of statistical kinetics has a large effect. Mean kinetics predict rapid burnout (99\% conversion) in less than 0.6 $\mathrm{sec}$, while statistical kinetics produce a long tail in the conversion curve that increases the time required for $99 \%$ burnout to $3.7 \mathrm{sec}$, about a factor of five increase. For the more reactive coal (Illinois \#6) burning at the higher temperature $(1650 \mathrm{~K})$, the effect is qualitatively similar, but much smaller in magnitude. The time required for $99 \%$ char conversion is increased from 0.12 to $0.16 \mathrm{sec}$. In both cases heterogeneity is a significant effect, and it is therefore recommended, for size classified samples, that statistical kinetics be used to describe or predict combustion behavior to high burnout. Incorporating the measured density distributions was seen to have a similar, but less significant effect under these conditions. 


\section{Simulations with particle size distributions}

Additional burnout simulations were carried out for coal samples with broad size distributions characteristic of industrial practice. No attempt was made to describe the complex multidimensional environment within furnaces - the goal of these one-dimensional calculations, rather, was to compare the burnout predictions of mean and statistical kinetics at relevant temperatures and oxygen concentrations, and in the presence of typical particle size distributions. Table 1 summarizes the simulation conditions and gives the results as carbon conversions, while Figure 6 presents the results as \% unburned carbon in ash. Simulations Ia,b were carried out at $1450 \mathrm{~K}$ using Pocahontas \#3 coal with a Rosin-Rammler distribution having 75\% less than 200 mesh $(75 \mu \mathrm{m})$. Under these conditions (relatively low temperature and reactivity) statistical kinetics can be seen to have a large effect, increasing the unburned carbon content of ash greatly from $0.32 \%$ to $8.3 \%$ (see Fig. 6).

Fig. 7 reveals the origin of the unburned carbon fraction after $2.4 \mathrm{sec}$ of residence time under the conditions of simulation Ib. Note that the axis represent particle sizes and reactivities in the parent (unreacted) fuel. Approximately $80 \%$ of the unburned carbon originates from the shaded area, representing that portion of the parent fuel with reactivity in the lowest 25 th percentile and with particle diameters from $50-200 \mu \mathrm{m}$. It is interesting to note that particles greater than about 200 $\mu \mathrm{m}$ will not burn out under these conditions regardless of their reactivity - even diffusion-limited burning is not fast enough to consume all the carbon in these large particles in the time available. This highlights the importance of minimizing the large particle fraction in pulverized fuel. For the size distributions used here $(70 \%<200 \mathrm{mesh})$, however, particles larger than $200 \mu \mathrm{m}$ are not numerous enough in the parent coal to make a large contribution to total unburned carbon. It is the particles that combine low reactivity and relatively large size that produce the bulk of the unburned carbon under the conditions in simulation $\mathrm{Ib}$.

Simulations IIa,b,c employed a more reactive coal and a higher gas temperature and did not show a significant effect of statistical kinetics (see Fig. 6). Incorporating the measured density distribution for Illinois \#6 in simulation IIC is also seen to have no significant effect. Based on a number of additional simulations the different behavior in simulation sets I and II can be explained as follows. At high reactivity the burnout is quite insensitive to changes in reactivity, as boundary layer diffusion is the primary rate-limiting step. As reactivity is decreased, a threshold value is reached, below which unburned carbon increases sharply. In simulation set I the mean reactivity lies close to this threshold, and the low reactivity tail of this distribution contributes greatly to unburned carbon. In simulation II the mean reactivity lies far from the threshold in the region where burnout is not particularly sensitive to char reactivity. 
Additional simulations were also carried out to explain the density effect. Mean particle density was seen to greatly effect burnout. It was observed, however, that carbon burnout varies in a nearly linear fashion with density under these condition, so incorporation of the distributions had little effect (the low density tail increases burnout to approximately compensate for the lower burnout of the high density tail).

A general comment can be made about the simulations. The overall burnout process for these heterogeneous samples is extremely nonlinear - most of the carbon consumption occurs in the first one-sixth of the residence time available, where the concentrations of fine and reactive particles are high. The effect is even more pronounced in simulations with decreasing temperature and oxygen profiles (not discussed in detail). In general, the final stages of combustion are observed to be extremely slow due to the combined effects of low oxygen concentration, low gas temperature, low reactivity, and larger mean size in the carbon particle population. It is believed that these fuel related effects, in addition to thermal deactivation[29], and the presence of nonuniform combustion conditions in large multi-burner installations [30-32], contribute substantially to the difficulty in achieving complete conversion in many commercial pulverized coal combustion systems.

\section{ACKNOWLEDGMENTS}

Financial support was provided to Sandia by the Pittsburgh Energy Technology Center's Advanced Research and Technology Development Program. Code development and burnout simulations were carried out at Brown University under subcontract from Sandia. The authors acknowledge the technical contributions of James Ross (TAD Technical Services), Donald Hardesty (Sandia), Reginald Mitchell (Stanford University), and useful discussions with Peter Walsh (EER), Philip Goldberg (DOE/PETC), and Arun Mehta (EPRI). 


\section{REFERENCES}

1. Essenhigh, R. H., in Chemistry of Coal Utilization, Second Supplementary Volume p. 1153 (M.A. Elliot, Ed.) John Wiley and Sons, New York, 1981.

2. Field, M. A. Comb and Flame, 14:237 (1970).

3. Smith I. W. and Tyler, R. J., Comb. Sci. and Tech. 9:87 (1974).

4. Young B. C. and Smith I. W., Comb. and Flame, 76:29 (1989).

5. Hurt, R. H. and R. E. Mitchell. Twenty-Fourth Symp. (Int.) on Combustion, pp. 1243 1250, The Combustion Institute, Pittsburgh, PA, (1992).

6. Sahu, R., Northrup, P. S. Flagan, R. C. and Gavalas, G. R. Comb. Sci. and Tech. 60:215 (1988).

7. Wall, T.F., A. G. Tate, J. G. Bailey, L. G. Jenness, R.E. Mitchell, and R. H. Hurt TwentyFourth Symp. (Int.) on Combustion, The Combustion Institute, Pittsburgh, PA, 1992.

8. Huang, G. Scaroni, A., Fuel 71:159 (1992).

9. Essenhigh, R.H., and Yorke, G.C., Fuel 44:177-186 (1965).

10. Thomas, C.G., Shibaoka, M., Gawronski, E., Gosnell, M.E., Brunckhorst, L.F., and Phong-anant, D., Fuel , 72:907 (1993).

11. Crelling J. C., Hippo, E. J., Woerner, B. A., and West, D. P. Jr., Fuel 71:151 (1992).

12. Bailey, J. B., Tate, A. G., Diessel, C. F. K., and Wall, T. F. Fuel 69:225 (1990).

13. Nandi, B. N., Brown, T. D., and Lee, G. K. "Inert Coal Macerals in Combustion," Fuel 56:125 (1977).

14. Shibaoka; M., Fuel 64:263 (1985).

15. Shibaoka, M., Fuel 65:449 (1986).

16. Morley, C. and Jones, R. B. Twenty-FirstSymp. (Int.) on Combustion; pp. 239-248, The Combustion Institute, Pittsburgh, PA. (1986).

17. Oka, N., Murayama, T., Matsuoka, H., Yamada, S., Yamada, T., Shinozaki, S., Shibaoka, M., and Thomas, C. G., Fuel Processing Technology 15:213-224 (1987).

18. Barta, L.E., Horvath, F., Beer, J.M., Sarofim, A.F., Twenty-Third Symp. (Int.) on Combustion, p. 1289, The Combustion Institute, Pittsburgh, 1991.

19. Monazam, E.R. and Maloney, D.J., Comb. Flame 99:733-741 (1994).

20. Mitchell, R. E., R. H. Hurt, L. L. Baxter, and D. R. Hardesty "Compilation of Sandia Coal Char Combustion Data and Kinetic Analyses: Milestone Report" Sandia Technical Report, SAND92-8208, June 1992. 
21. Fletcher, T.H. and D. R. Hardesty "Compilation of Sandia Coal Devolatilization Data: Milestone Report" Sandia Technical Report, SAND92-8209, May 1992.

22. Hurt, R. H. and Davis, K. A., Twenty-Fifth Symp. (Int.) on Combustion, pp. 561-568, The Combustion Institute, Pittsburgh, 1994.

23. Maloney, D.J., Lawson, L.O., Fasching, G.E., Monazam, E.R, Aerosol Sci. Technol. 22:60-72 (1995).

24. Maloney, D.J., Lawson, L.O., Fasching, G.E., Monazam, E.R., Rev. Scie. Instru. 66:36153622 (1995).

25. Hurt, R. H. Energy and Fuels 7:721-733 (1993).

26. Mitchell, R. E. Twenty-Third Symp. (Int.) on Combustion, p. 1297, The Combustion Institute, Pittsburgh, PA, 1991.

27. Smith, I.W., Fuel 57:409 (1978).

28. Charpenay, S., Serio, M.A., and Solomon, P.R., Twenty-Fourth Symp. (Int.) on Combustion, pp. 1189-1197, The Combustion Institute, Pittsburgh, 1992.

29. Hurt, R.H., Davis, K.A., Yang, N.Y.C., and Headley, T.R., and Mitchell, G.D., Fuel, 74:1297-1306 (1995).

30. Walsh, P.M., Xie, J., Douglas, R.E., Battista, J., Zawadski, E., Fuel 73:1074 (1994).

31. Walsh, P.M., American Flame Research Committee, 1995 Fall International Symposium, Monterey, California, 1995.

32. Chen, J. Y., Mann, A. P., and Kent, J. H. Twenty-Fourth Symp. (Int.) on Combustion, pp. 1189-1197, pp. 1381-1389, The Combustion Institute, Pittsburgh, 1992. 


\section{FIGURE CAPTIONS}

Figure 1 Example of entrained flow reactor data in the form of measured char particle temperatures and sizes in a fixed combustion environment (local gas temperature $1645 \mathrm{~K}, 6$ vol-\% oxygen). Open symbols are single particle data for Pocahontas \#3 coal; closed symbols are median sizes and temperatures for a set of coals of various rank.

Figure 2 Measured and predicted temperature variances for a series of coal chars burning in three different combustion environments. Symbols are measured variances; dashed lines are model predictions. All char conversions are less than $45 \%$.

Figure 3 Distributions of pulverized char particle density measured by the electrodynamic balance technique.

Figure 4 Example of measured and predicted particle temperature distributions for Pocahontas \#3 coal char. Combustion conditions are 12 mole-\% oxygen and a gas temperature of $1645 \mathrm{~K}$. Shown in the inset is the gamma distribution of preexponential factors on which the prediction is based.

Figure 5 Calculations showing the effect of distributed reactivity during combustion of size classified coal particles. Initial particle diameters are $100 \mu \mathrm{m}$ and oxygen concentration is constant at 7 mole-\%. For Illinois \#6 coal char: $T_{g}=1650 \mathrm{~K}$ and $A_{\text {mean }}=14.4 \mathrm{~g}$-carbon $/ \mathrm{s}-\mathrm{cm}^{2}$-atm 0.5 . For the Pocahontas $\# 3$ coal char, $\mathrm{T}_{\mathrm{g}}=1450 \mathrm{~K}$ and $A_{\text {mean }}=8.0 \mathrm{~g}$-carbon $/ \mathrm{s}-\mathrm{cm}^{2}$-atm 0.5 .

Figure 6 The effect of statistical kinetics on carbon burnout expressed as \%unburned carbon in ash. Results are from simulations described in Table 1. Coal ash content: $10 \%$.

Figure 7 The origin of unburned carbon in simulation Ib. The solid line divides the sizereactivity space intor regions of complete and incomplete burnout. The cross, $\mathrm{X}$, makrs the position of the mean size and reactivity in the parent fuel. Sector entries are the percentages of the total unburned carbon that originate from the given size and reactivity bin in the parent fuel (sectors add to $100 \%$ of the total unburned carbon). The shaded region at low reactivity represents approximately $80 \%$ of the total unburned carbon. 


\section{TABLES AND FIGURES}

\section{Table 1}

Conditions in the Simulations with Particle Size Distributions ${ }^{a}$

\begin{tabular}{cllllll}
\hline Label & Coal & $\begin{array}{c}\text { Gas } \\
\text { Temp. }\end{array}$ & $\begin{array}{c}\text { Residence } \\
\text { Time }\end{array}$ & $\begin{array}{c}\text { Carbon } \\
\text { Density }\end{array}$ & $\begin{array}{c}\text { Kinetic } \\
\text { Scheme }\end{array}$ & $\begin{array}{c}\text { Char } \\
\text { Conversion }\end{array}$ \\
Ia & Pocahontas & $1450 \mathrm{~K}$ & $2.4 \mathrm{~s}$ & 0.63 & mean & $99.96 \%$ \\
Ib & Pocahontas & $1450 \mathrm{~K}$ & $2.4 \mathrm{~s}$ & 0.63 & statistical & $98.92 \%$ \\
IIa & Illinois & $1650 \mathrm{~K}$ & $0.58 \mathrm{~s}$ & 0.36 & mean & $99.30 \%$ \\
IIb & Illinois & $1650 \mathrm{~K}$ & $0.58 \mathrm{~s}$ & 0.36 & statistical & $99.16 \%$ \\
IIc & Illinois & $1650 \mathrm{~K}$ & $0.58 \mathrm{~s}$ & statistical & mean & $99.24 \%$ \\
\hline
\end{tabular}

a All simulations employed a Rosin-Ramler size distribution (70\% through 200 mesh), and a fixed oxygen concentration of 7 vol-\%. Mean char properties taken from Mitchell et al.[20]. 


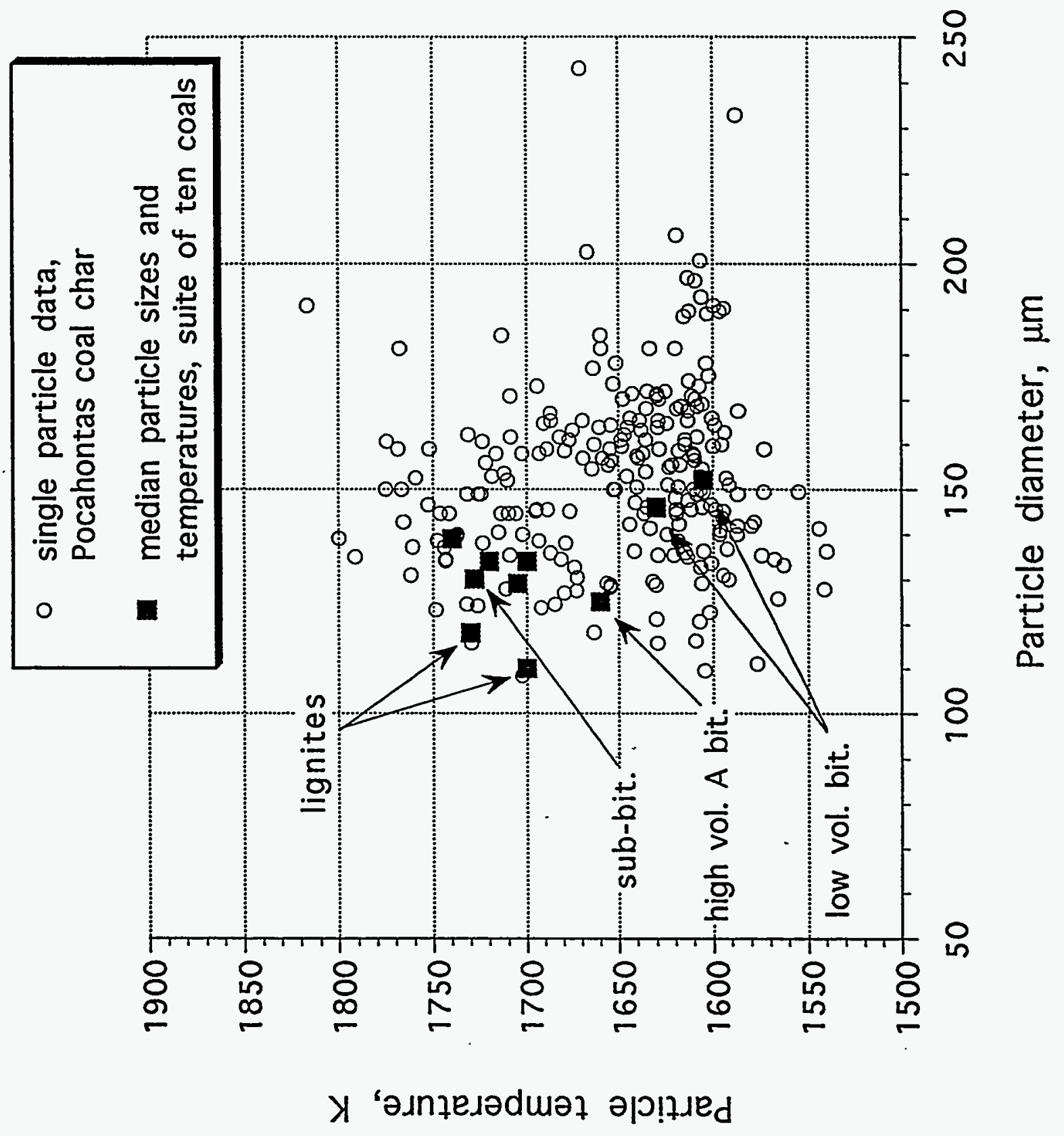



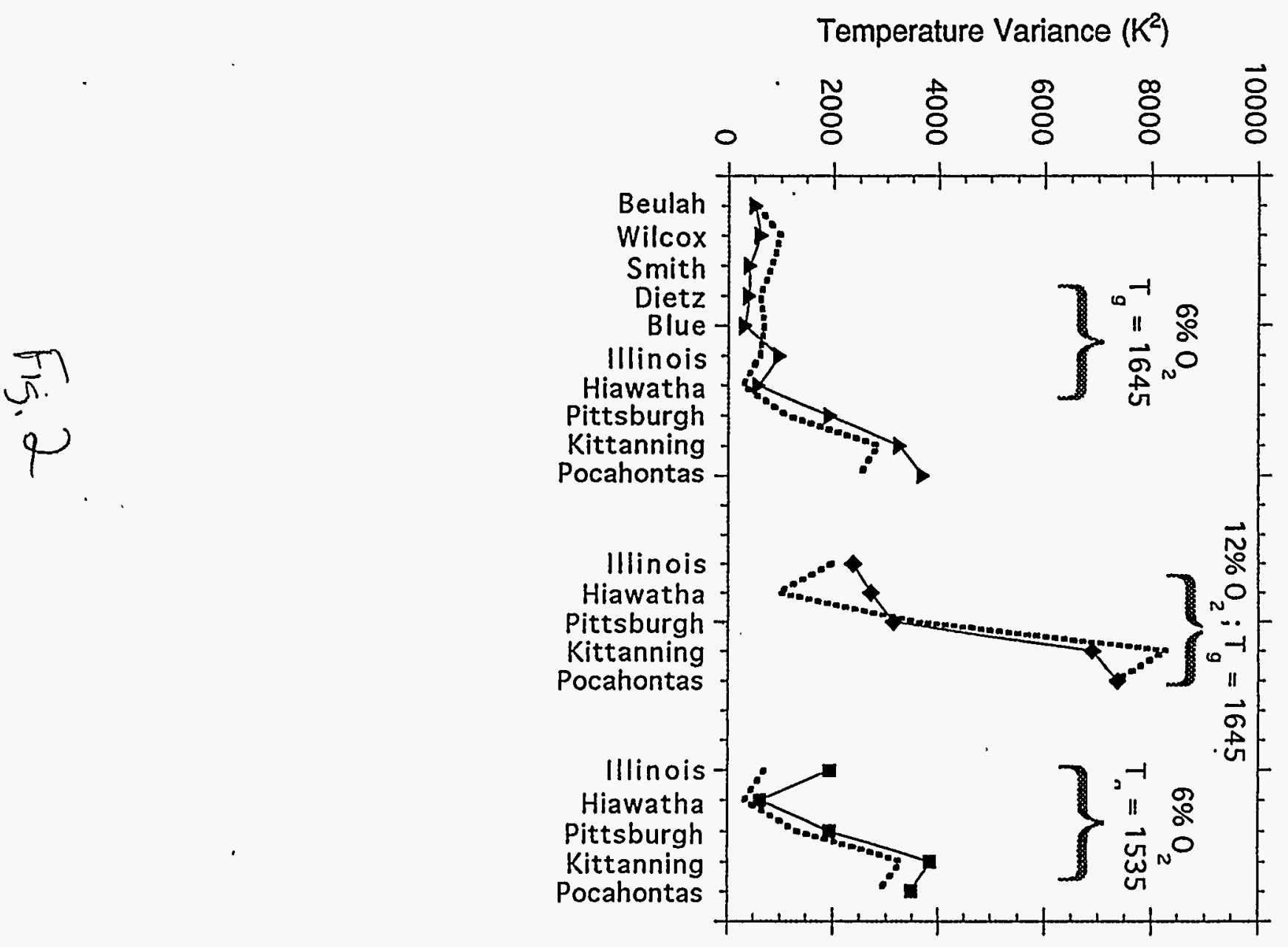

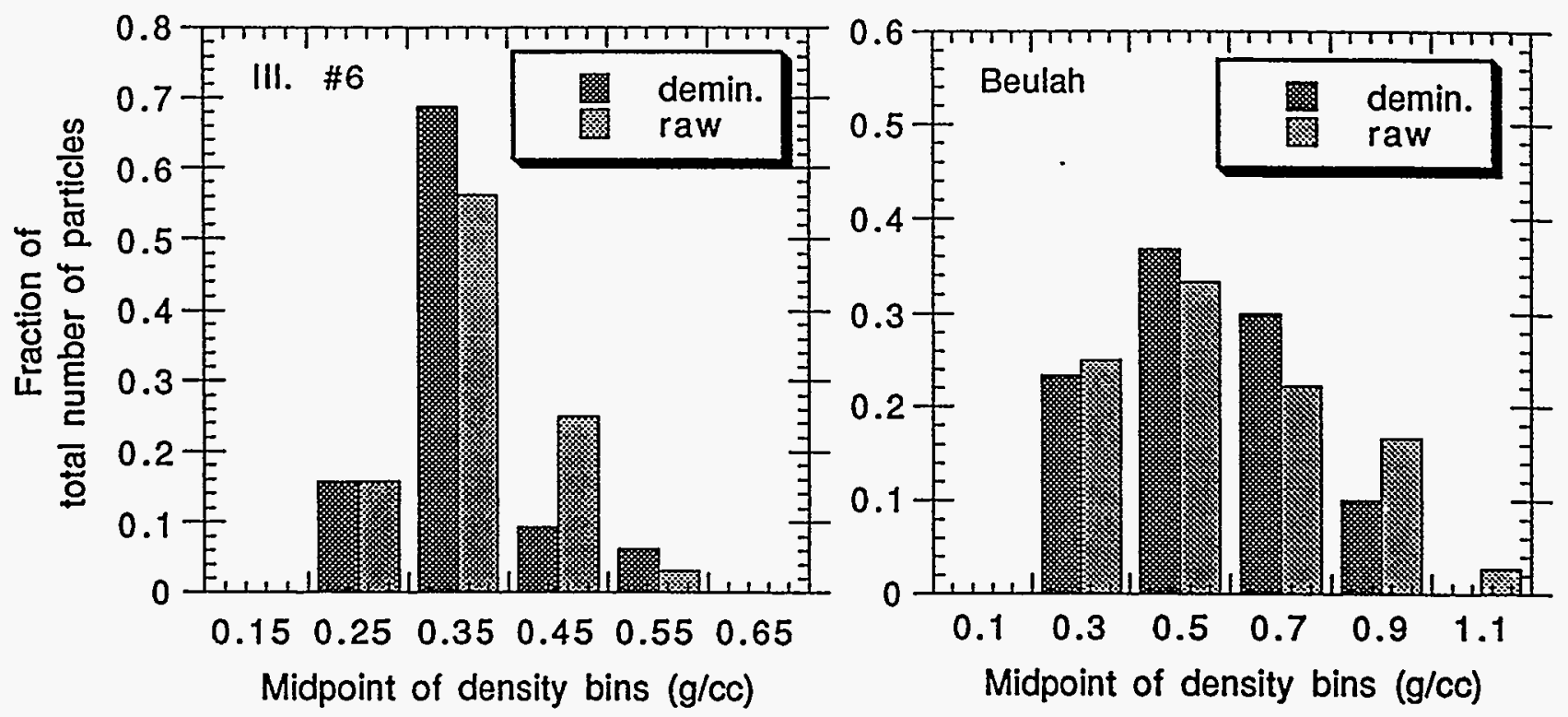

Fig. 


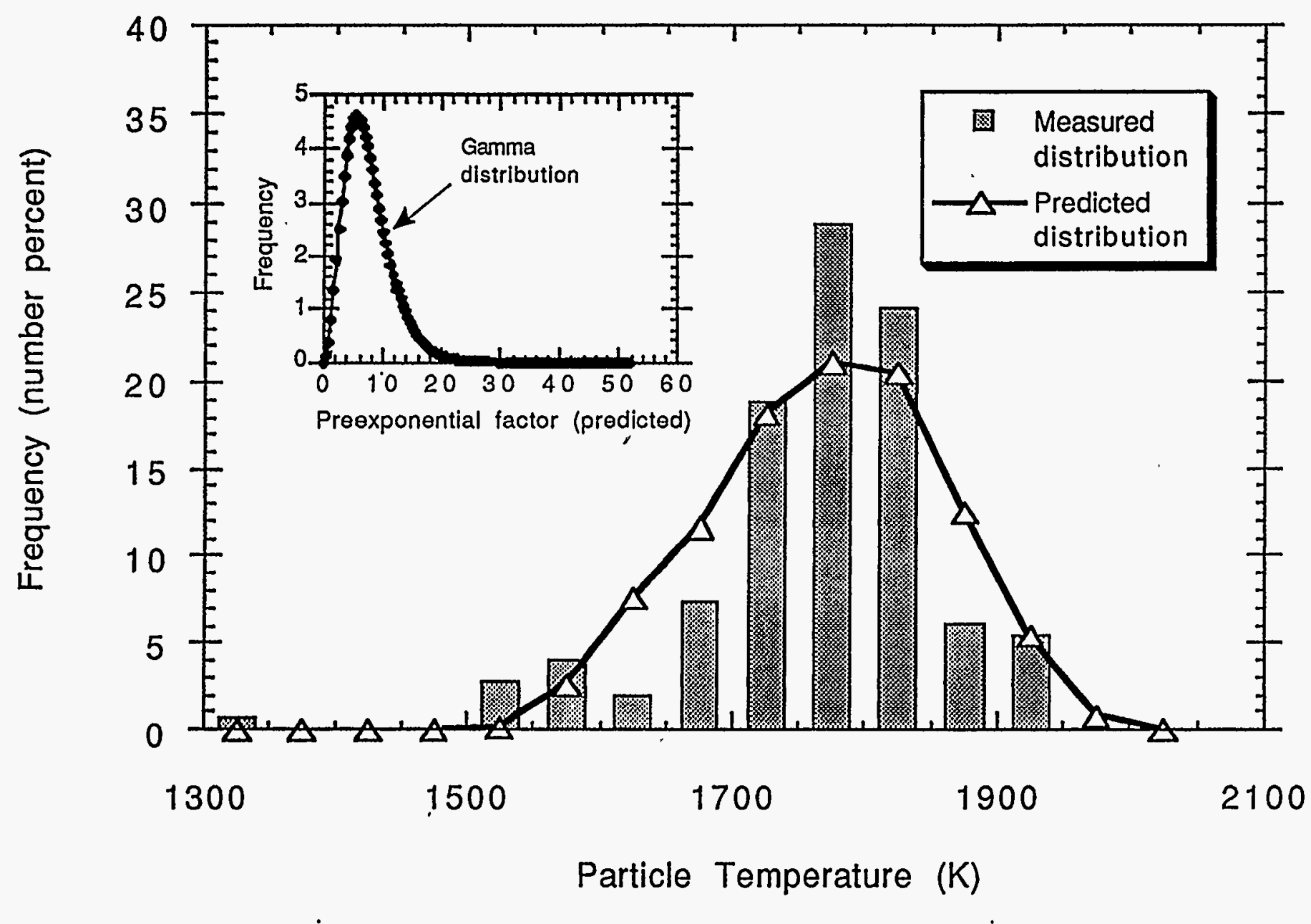

Fig. 4 

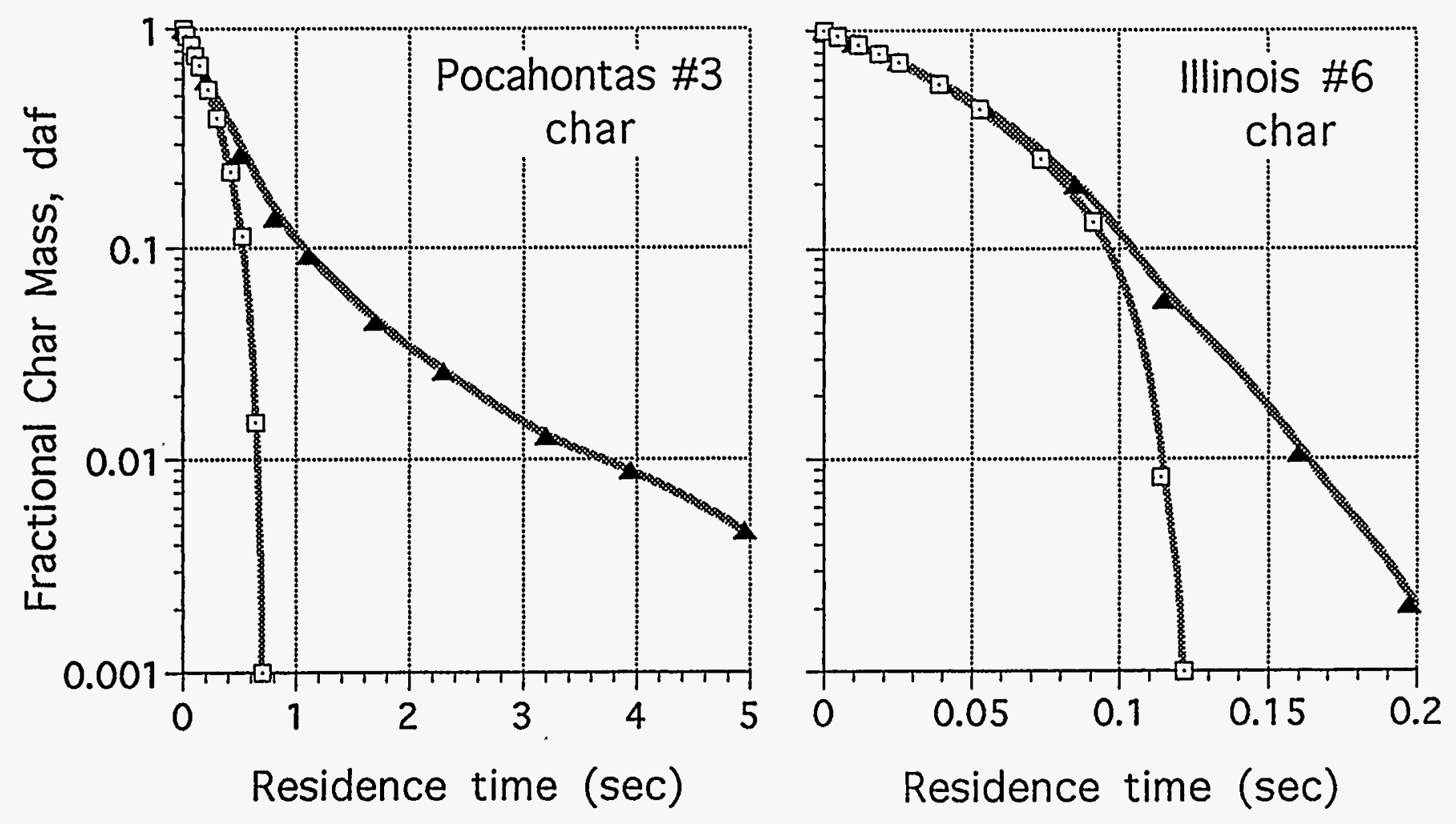

Fig. 5 


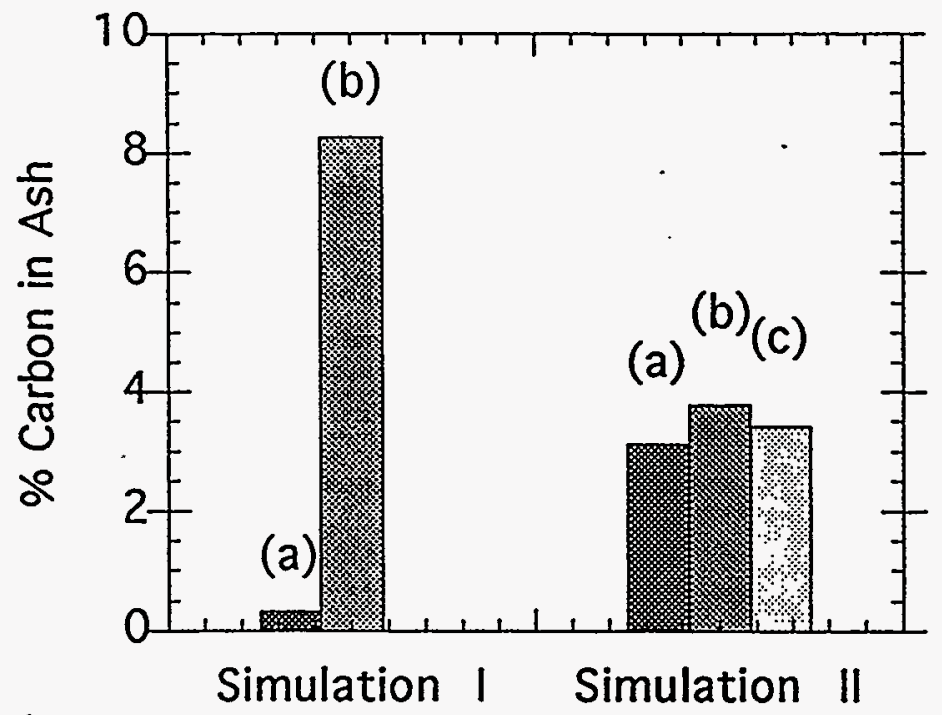

Fig. 6 


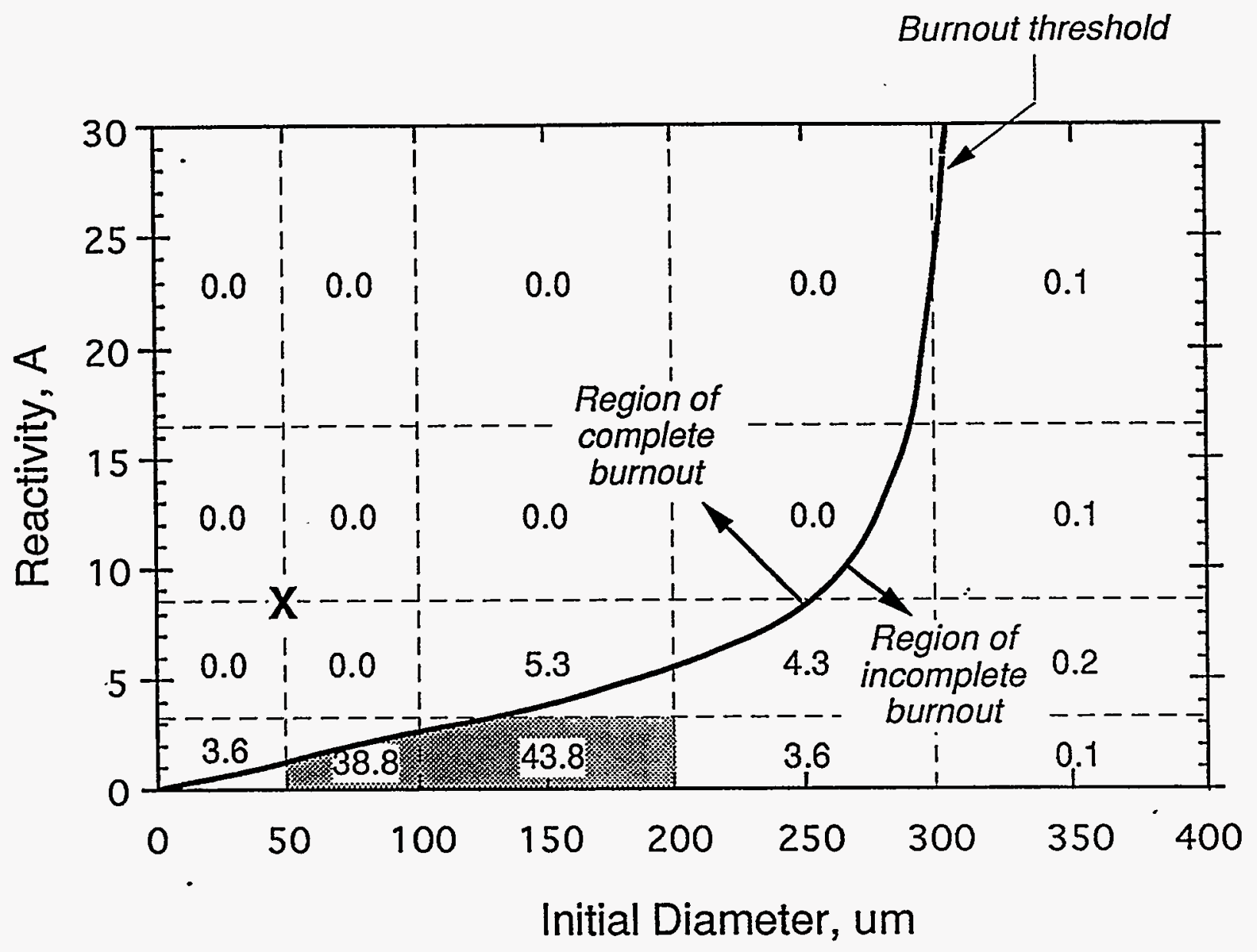

Fig. 7 